\title{
Mass Transfer Performance of a String Film Reactor: A Bioreactor Design for Aerobic Methane Bioconversion
}

\author{
Rina Mariyana ${ }^{1}$, Min-Sik Kim ${ }^{2}$, Chae Il Lim ${ }^{3}$, Tae Wan Kim ${ }^{4}$, Si Jae Park ${ }^{5}$, Byung-Keun Oh ${ }^{3}$, \\ Jinwon Lee ${ }^{3}$ and Jeong-Geol $\mathrm{Na}^{3, *(\mathbb{D})}$ \\ 1 PT Rekayasa Industri, Kalibata Timur 1 Street No.36, Jakarta 12740, Indonesia; na.mariyana@gmail.com \\ 2 Biomass and Waste Energy Laboratory, Korea Institute of Energy Research, 152 Gajeong-ro, Yuseong-Gu, \\ Daejeon 34129, Korea; kms0540@kier.re.kr \\ 3 Department of Chemical and Biomolecular Engineering, Sogang University, Seoul 04107, Korea; \\ codlf0620@naver.com (C.I.L.); bkoh@sogang.ac.kr (B.-K.O.); jinwonlee@sogang.ac.kr (J.L.) \\ 4 Department of Biotechnology and Bioengineering, Chonnam National University, Gwangju 61186, Korea; \\ chekimtw@chonnam.ac.kr \\ 5 Division of Chemical Engineering and Materials Science, Ewha Womans University, Seoul 03760, Korea; \\ parksjdr@gmail.com \\ * Correspondence: narosu@sogang.ac.kr; Tel.: +82-2-705-7955
}

Received: 25 September 2018; Accepted: 22 October 2018; Published: 24 October 2018

\begin{abstract}
The mass transfer performance of a string film reactor (SFR)—a bioreactor design for the aerobic bioconversion of methane-was investigated. The results showed that the SFR could achieve high mass transfer performance of gases, and the highest values of the mass transfer coefficients for oxygen and methane were $877.1 \mathrm{~h}^{-1}$ and $408.0 \mathrm{~h}^{-1}$, respectively. There were similar mass transfer coefficients for oxygen and methane in absorption experiments using air, methane, and air-methane mixed gas under the same liquid flow rate conditions, implying that each gas is delivered into the liquid without mutual interaction. The mass transfer performance of the SFR was significantly influenced by the liquid flow rate and the hydrophilicity of the string material, whereas the magnitude of the gas flow rate effect on the mass transfer performance depended on both the tested liquid flow rate and the gas flow rate. Furthermore, the mass transfer performance of the SFR was compared with those of other types of bioreactors.
\end{abstract}

Keywords: aerobic methane bioconversion; bioreactor; string film reactor; mass transfer performance

\section{Introduction}

Natural gas conversion into liquid chemicals has become attractive [1] due to the rapid rise in natural gas production [2,3], the tremendous demand for liquid transportation fuel [2], and its compatibility with current vehicle engines and infrastructure [1,4]. However, the current conversion approach, which employs the Fischer-Tropsch process, still faces several obstacles preventing its commercialization owing to its high capital requirements and energy-intensive nature [1,4]. The aerobic bioconversion of methane- the main component of natural gas-by using methanotrophic microorganisms as biocatalysts has shown good potential as an alternative to the Fischer-Tropsch process due to its high selectivity, ambient operating temperature, one-step direct process, and reduced technological complexity [1,4-7]. Therefore, it can be applied to monetize small sources of natural gas, such as stranded and flared natural gas. Recently, microorganisms, as host strains for bio-based production, have been extensively engineered to make them efficient microbial cell factories that are compatible with currently available production and product purification processes 
by using alternative feedstocks to petroleum [8]. For example, based on these metabolic engineering strategies, Methylomicrobium alcaliphilum $20 \mathrm{Z}$ was successfully engineered to produce 2,3-butanediol from methane [9]. Even though host strains can be successfully developed to produce target products by performing metabolic engineering strategies, appropriate fermentation processes of these host strains should also be developed to realize the efficient production of target products by considering several factors to increase the efficiency of product formation. Thus, insufficient supply of methane and oxygen to the microbial catalysts because of low mass transfer rate and the solubility of the gas in the aqueous phase should be addressed in order to realize the commercialization of the aerobic bioconversion of methane, which has been limited by the low titer of the product, low productivity, and low production yields. These have resulted from slow process kinetics and low metabolic energy efficiency, among other factors [1].

A reactor design and process development deliberately reflecting microbial characteristics can help overcome the current limit on microbial catalyst performance, especially in fermentation using $\mathrm{C} 1$ gas as a carbon substrate. The hydrogen productivity of Thermococcus onnurineus NA1, an archaeal strain which has good potential to endure high pressure, was dramatically enhanced by developing a pressurizing bioreactor [10]. Thus, a well-developed reactor design is very significant for maximizing the activity potential of engineered microbial catalysts. To deal with poor characteristics of gas transfer, either the volumetric liquid-side mass transfer coefficient $k_{L} a$ or the concentration driving force [10], which are the two main factors affecting the mass transfer rate as in the following equation, should be improved.

$$
\frac{d C}{d t}=k_{L} a\left(C^{*}-C\right)-Q_{C} x
$$

The common approaches that are employed to improve the volumetric liquid-side mass transfer coefficient $k_{L} a$ involve the optimization of operating parameters and the modification of the bioreactor configuration. A number of approaches have been employed in various types of bioreactors, for example, by increasing the mechanical agitation rate [11,12], investigating several types of impeller configuration [12], and applying a spinning disk microbubble generator [13] in a stirred tank reactor; by testing various types of membrane material [11,14] and adding an external diffuser [15] to a hollow fiber membrane reactor; by modifying the geometry of the reactor [16], testing various gas distributor designs [16], and by applying vibration excitement [17] in a bubble column reactor [18]; by modifying the reactor configuration with the addition of a semipermeable membrane [19] and by optimizing the geometry of the reactor [20] in an air-lift reactor.

The improvement in the value of $k_{L} a$ was confirmed for various bioreactor types, but the bioreactors that were utilized have major drawbacks that can reduce their feasibility for aerobic methane bioconversion application in terms of their operability. These include their high mechanical burden and membrane fouling problems [21-23]. Most strategies have focused on the transfer of oxygen in aerobic cultures, where the main objective of gas transfer is to maintain the dissolved oxygen concentration at a desired level. Unlike aerobic fermentation with sugar, the goal of performing the bioconversion of methane is to produce bulk chemicals from low-priced raw materials efficiently and economically, and it is therefore important to achieve a low energy consumption and high conversion of feed gas. In this respect, the direct application of conventional cases requires careful consideration.

To develop a mass transfer system for methane bioconversion while addressing the obstacles of existing systems, a string film reactor (SFR) was designed and implemented in this study. An SFR is a column reactor in which the contact between liquid and gas takes place on the strings (Figure 1). The SFR was designed to tackle the drawbacks of existing bioreactors through the use of hydrophilic strings that are able to direct and to guide the flow of liquid in a desired manner, thereby preventing nonuniform liquid flow; the formation of a thin film on the surface of the strings, which can decrease the mass transfer resistance; and the use of cell immobilization on the strings as a biofilm to enable high-cell-density culture inside the reactor without causing fouling problems. Furthermore, the SFR 
can be easily scaled up or scaled down to the desired production volume by specifying the column size and the number of strings.

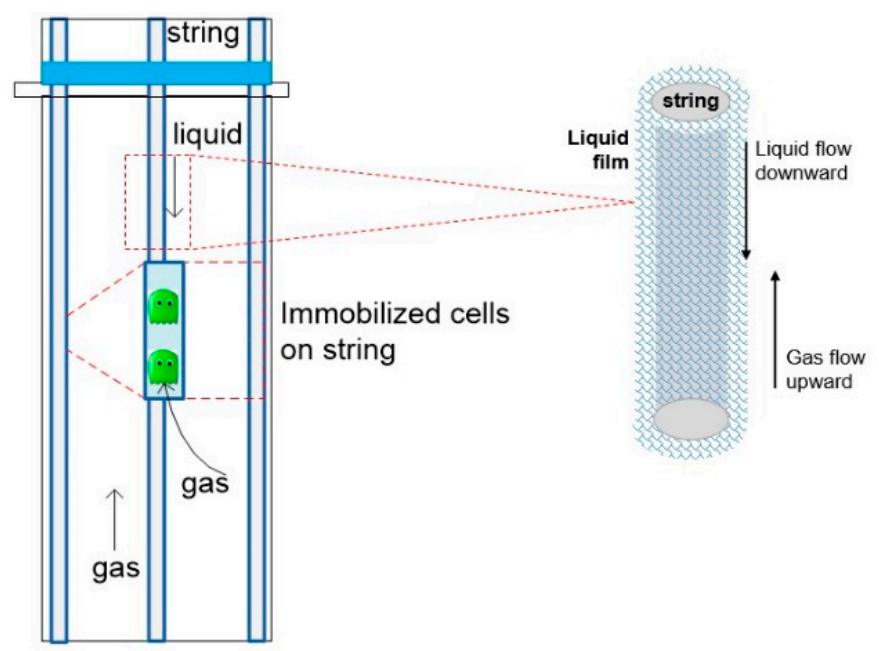

Figure 1. The concept of the string film reactor (SFR).

To assess the mass transfer performance of the SFR, this study explored the effects of the liquid flow rate, gas flow rate, and string materials on the $k_{L} a$ value of oxygen. In addition, because both methane and oxygen participate in the aerobic bioconversion of methane as limiting substrates, the mass transfer characteristics of each gas must be considered independently. In this study, considering the real environment of the system, we investigated the mass transfer behavior of the gases when methane, air, or a mixed gas composed of both methane and air were applied as feed.

\section{Results}

\subsection{Effect of Liquid Flow Guidance by Strings on Mass Transfer Performance}

To investigate the effect of varying the liquid flow direction on the mass transfer efficiency, the mass transfer coefficients for oxygen were measured at various liquid flow rates with and without the string in the system. As shown in Figure 2, the mass transfer performance of the SFR was considerably influenced by the liquid flow rate. It was observed that $k_{L} a$ values increased by 3.39 times and 2.83 times with and without the string, respectively, when the liquid flow rate increased from $100 \mathrm{~mL} / \mathrm{min}$ to $500 \mathrm{~mL} / \mathrm{min}$.

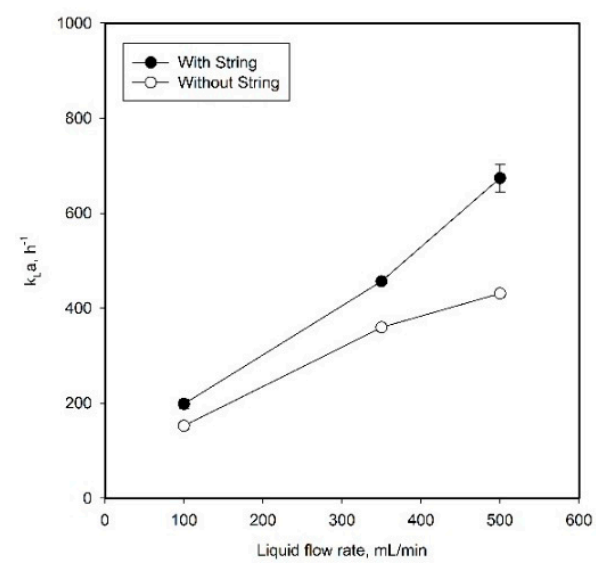

Figure 2. Volumetric mass transfer coefficients for oxygen for the SFR with the string (closed circles) and without the string (open circles). 
The presence of strings also influenced the mass transfer performance, and the mass transfer coefficients with strings increased significantly compared to the corresponding values without the string. At a gas flow rate of $350 \mathrm{~mL} / \mathrm{min}$, the $\mathrm{DO}$ (dissolved oxygen) value in the steady state without the string was only $60.5 \%$, while it was $72.5 \%$ with strings, exhibiting enhanced oxygen transfer. As a result, the $k_{L} a$ value was $455.72 \mathrm{~h}^{-1}$, which is 1.26 times larger than that obtained without the string.

\subsection{Investigation of Mass Transfer Characteristics in SFR Using Methane-Air Mixed Gas}

The mass transfer coefficients obtained for methane were measured at various liquid flow rates. As in the experiments with air, the mass transfer coefficients increased with the liquid flow rates (Figure 3a), but the extent of this increase was reduced with the liquid flow rates, while the variances of the $k_{L} a$ values under the same conditions increased. The mass transfer coefficient of methane at the liquid flow rate of $100 \mathrm{~mL} / \mathrm{min}$ was $79.0 \mathrm{~h}^{-1}$ and increased to $408.0 \mathrm{~h}^{-1}$ at a liquid flow rate of $500 \mathrm{~mL} / \mathrm{min}$.

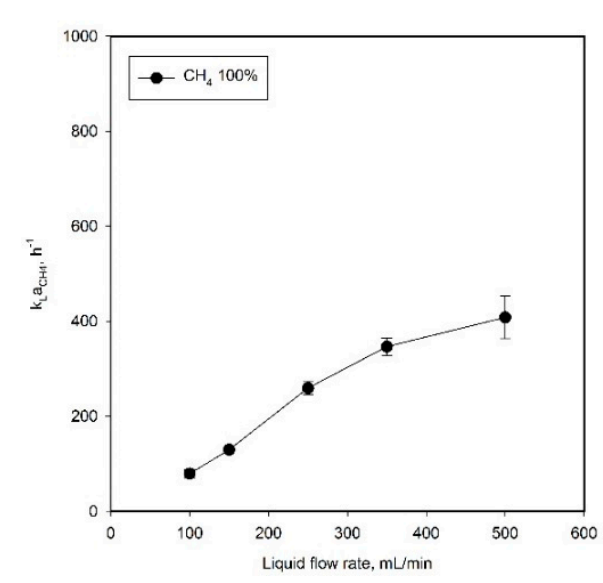

(a)

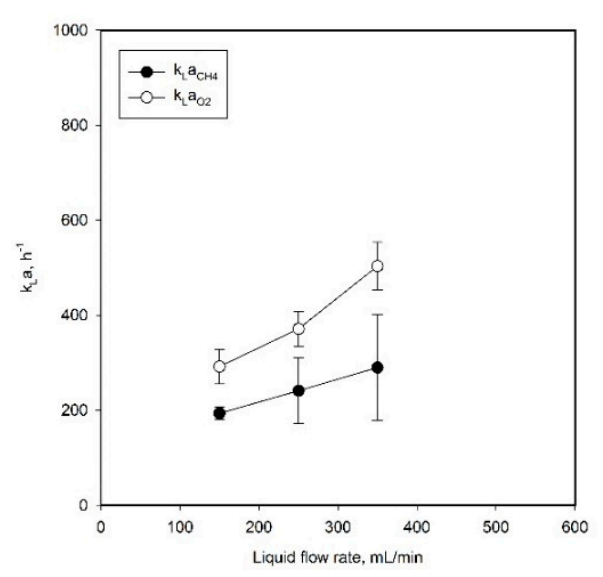

(b)

Figure 3. Volumetric mass transfer coefficients for (a) methane in the system using $100 \%$ methane gas and (b) methane (closed circles) and oxygen (open circles) using the gas containing $30 \%$ methane and $70 \%$ air.

To evaluate the feasibility of the SFR system for methane conversion and to investigate the mass transfer characteristics of the system using the gas containing air and methane, the mass transfer coefficients for each gas were determined at various liquid flow rates. A mixed gas composed of $30 \%$ methane and $70 \%$ air, which is commonly used for the bioconversion of methane [5], was supplied to the system as feed gas. Although there were some fluctuations-possibly caused by a disturbance in the measurement of dissolved methane by the gas chromatography, owing to the presence of impurities including air in the sample tube (see Section 4.2 for the detailed method of measurement) - the $k_{L} a$ values were similar to those obtained in the cases using single-component gas (Figure 3b). When the liquid flow rate was $350 \mathrm{~mL} / \mathrm{min}$, the mass transfer coefficients of methane and oxygen were $289.7 \mathrm{~h}^{-1}$ and $503.2 \mathrm{~h}^{-1}$, respectively.

\subsection{Improvement of Mass Transfer Performance by Using Hydrophilic Porous Strings}

Absorption experiments for oxygen were conducted to investigate the effect of the hydrophilicity of the string on the mass transfer performance. Two types of string material were tested. One was of the fabric that was used in the previous sections and the other was of felt. Because hydrophilic behavior is correlated with the critical surface tension of the material [24], the felt material, which consists purely of cotton, should be more hydrophilic than the fabric material, which consists of a mixture of nylon and cotton, owing to the higher critical surface tension value of cotton $(60-70 \mathrm{mN} / \mathrm{m})$ [25] relative to 
that of nylon (30-44 mN/m) [26]. Also, the felt material used in this study was porous and was able to absorb larger amounts of water than the fabric material.

The hydrophilic property of the string material is in accordance with the hydrophilic behavior of the material that was observed in this experiment. The felt material was able to be perfectly wetted by the water and could maintain sufficient contact with water without forming droplets on its surfaces. However, for the case involving fabric strings, the liquid flow was not stable and the droplets were splashed on the wall surface of the system; this tendency became more severe with the increase of the liquid flow rate. The mass transfer performance of the SFR was affected by the hydrophilicity of the string material, as shown in Figure $4 \mathrm{a}$. The felt material, which is more hydrophilic, achieved $k_{L} a$ values that were about 1.3 times higher than those of the fabric material.

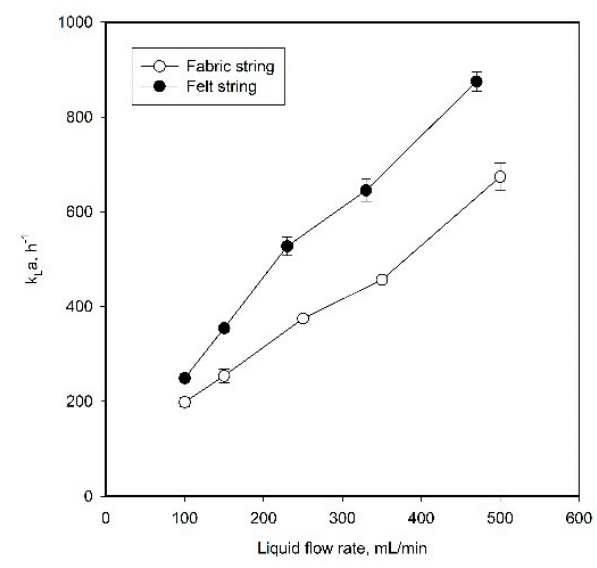

(a)

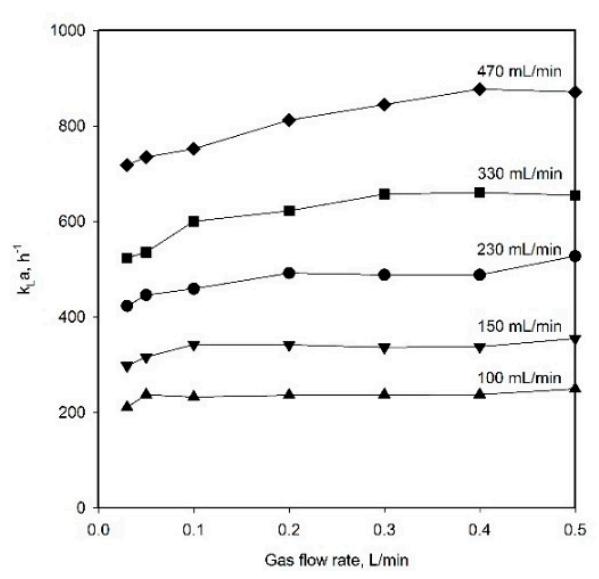

(b)

Figure 4. Mass transfer performance of the SFR using felt strings: (a) comparison of the volumetric mass transfer coefficients for oxygen with fabric strings (open circles) and felt strings (closed circles) and $(\mathbf{b})$ effect of the gas flow rate on the mass transfer coefficients.

The effects of the gas flow rates on $k_{L} a$ values were observed in the SFR using the felt string material. The experiments were conducted by gradually decreasing the gas flow rate while the liquid flow rate was kept constant. As shown in Figure $4 b$, the mass transfer performance of the SFR was not affected by the gas flow rate above $0.4 \mathrm{~L} / \mathrm{min}$ for each tested liquid flow rate. However, at a gas flow rate below $0.4 \mathrm{~L} / \mathrm{min}$, the magnitude of the effects of the gas flow rate on the mass transfer performance depends on both of the liquid flow rate and the gas flow rate. It was also observed that the $k_{L} a$ value was independent of the gas flow rate after it reached a particular gas flow rate, which is defined as the critical gas flow rate. Therefore, it should be noted that it is important to operate the SFR at the critical gas flow rate in order to obtain the optimum value of $k_{L} a$ for low gas throughputs. For each tested liquid flow rate, the critical gas flow rates obtained in this study are presented in Table 1.

Table 1. Critical gas flow rate at each tested liquid flow rate.

\begin{tabular}{cc}
\hline Liquid Flow Rate (mL/min) & Critical Gas Flow Rate (L/min) \\
\hline 100 & 0.05 \\
150 & 0.10 \\
250 & 0.20 \\
350 & 0.30 \\
500 & 0.40 \\
\hline
\end{tabular}




\section{Discussion}

In this study, the SFR system aimed to increase the mass transfer rate by efficiently manipulating the contact between the gas and liquid. The experiment results obtained indicate that the liquid flow rate and the hydrophilicity of the string material are parameters that need to be considered for the design and operation of the SFR.

The positive effects of the liquid flow rates on $k_{L} a$ could be well explained by the physical concept behind Higbie's model. According to Higbie's model, there is a continual attachment wherein the liquid element is in contact with the gas for particular exposure time $\theta$ and absorbs the gas by molecular diffusion which increases rapidly initially and decreases with time [27]. At a high liquid flow rate, the periodic replacement of the liquid element at the gas-liquid interface is more frequent, and the rate of gas absorption therefore becomes higher.

The flow pattern of liquid on the surface of the strings is also very important with regards to realizing an improved mass transfer performance, as can be observed clearly from the comparison of $k_{L} a$ values for the cases with and without string, as well as for the cases with the strings having different hydrophilicities. When the direction of flow of the liquid was varied by the strings present in the SFR, the contact of gas and liquid at the interface was stabilized, thus allowing improved mass transfer performance. These effects were further enhanced when the hydrophilic porous string was used. This may be responsible for the increase in the interfacial area of the contact, as was also reported by Onda et al. [28] and Han et al. [29]. According to their results, a positive correlation between the hydrophilicity of the packing material and the contact area was observed in their mass transfer equation for a packed bed reactor.

The biological conversion of methane was carried out primarily in the aerobic condition, and both methane and oxygen should therefore be sufficiently supplied to the system. Most studies on the gas transfer systems that have been reported in the literature have been evaluated by studying the performance with oxygen, and very little empirical work has been done to investigate methane or methane-oxygen transfer.

According to the results presented in this study, the $k_{L} a$ values for oxygen and methane in the system obtained from $100 \%$ air and $100 \%$ methane were similar to those of the mixed gas containing $30 \%$ methane (Figure $5 \mathrm{a}$ ), implying that the $k_{L} a$ values obtained for oxygen and methane in the system are independent of the composition of the gas. However, the mass transfer coefficient values obtained for methane were lower than those for oxygen under the same conditions. A strategy to complement the low efficiency of methane transfer should be established. It is generally known that the $k_{L} a$ value of a gas is closely related to its diffusivity [30]. Based on the diffusivity of methane and oxygen [31], the $k_{L} a$ value for methane was estimated and compared with the measured values (Figure $5 \mathrm{~b}$ ). The mass transfer coefficients for methane at the liquid flow rates of $250 \mathrm{~mL} / \mathrm{min}$ and $350 \mathrm{~mL} / \mathrm{min}$ were about $70 \%$ of the corresponding values for oxygen, but values that were lower than $70 \%$ of the $k_{L} a$ value for oxygen were obtained at lower liquid flow rates, while higher values were obtained at higher flow rates. Further study is required to better understand the differences in the mass transfer coefficients for different gases.

To assess the mass transfer capability of the SFR, the highest $k_{L} a$ value obtained in this study for oxygen was compared with those obtained from other studies for various types of bioreactors. To enable an equivalent comparison among reactors, operating conditions, including the gas flow, liquid flow, and liquid volume, are presented. As can be seen in Table 2, the $k_{L} a$ value of the SFR was higher than that of the stirred tank reactor reported by Orgill et al. [11] and Karimi et al. [12], whereas the stirred tank reactor was operated at a high agitation speed of 900-1000 rpm. This confirmed that the SFR was able to efficiently transfer the gas to the liquid with lower energy consumption than the stirred tank reactor, owing to its capability. This could minimize mass transfer resistance by the formation of liquid film without relying on a high agitation speed as in the stirred tank reactor. In addition, the $k_{L} a$ value of the SFR was higher than that of the bubble column reactor reported by Lau et al. [15], Khrisna and Ellenberger [17], Bekassy et al. [20], and Budzynski et al. [32], despite the 
lower superficial gas velocity of the SFR. The packed bed-trickle flow reactor should be compared with the SFR at a comparable value of gas flow rate in order to have an equivalent comparison because the mass transfer of the packed bed-trickle flow reactor is significantly affected by the gas flow rate [11,27]. For a gas flow rate of around $0.1 \mathrm{~L} / \mathrm{min}$, the SFR outperformed the packed bed-trickle flow reactor, with $k_{L} a$ values of $752.0 \mathrm{~h}^{-1}$ (not shown in Table 2 ) and $421 \mathrm{~h}^{-1}$, respectively. The SFR exhibited lower performance compared with the hollow fiber membrane reactor. However, there is an advantage in terms of simplicity and operability.

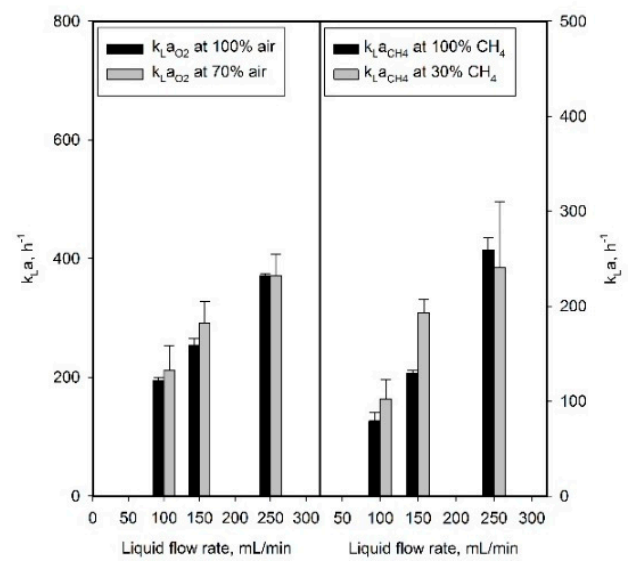

(a)

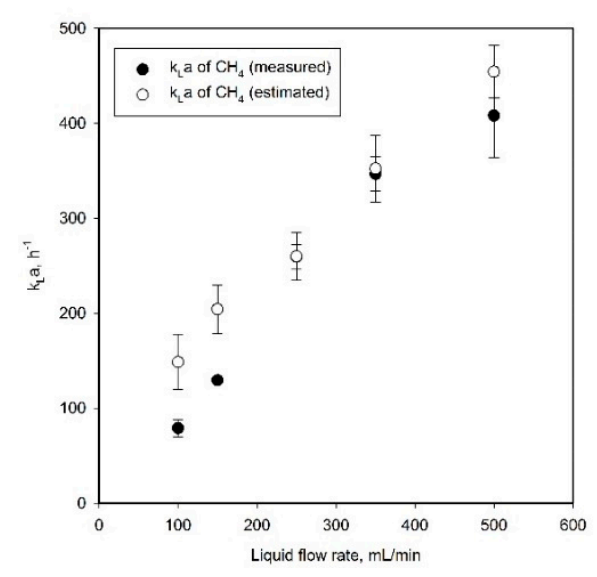

(b)

Figure 5. Comparison of the mass transfer characteristics in the SFR using different feeding gases: (a) the volumetric mass transfer coefficients for oxygen (left side) and methane (right side) and (b) the measured (closed circle) and estimated (open circle) volumetric mass transfer coefficients obtained for methane.

Table 2. Mass transfer coefficients for oxygen for the SFR and other reactor types.

\begin{tabular}{|c|c|c|c|c|c|c|c|}
\hline \multirow[b]{2}{*}{ Reactor Type } & \multicolumn{5}{|c|}{ Operating Condition } & \multirow[b]{2}{*}{$\begin{array}{c}\text { Highest } k_{L} a \\
\left(\mathrm{~h}^{-1}\right) \text { Obtained } \\
\text { for Oxygen }\end{array}$} & \multirow[b]{2}{*}{ Reference } \\
\hline & $\begin{array}{c}\text { Gas Flow } \\
\text { Rate } \\
\text { (mL/min) }\end{array}$ & $\begin{array}{c}\text { Liquid } \\
\text { Flow Rate } \\
\text { (L/min) }\end{array}$ & $\begin{array}{l}\text { Superficial } \\
\text { Gas Velocity } \\
(\mathrm{cm} / \mathrm{s})\end{array}$ & $\begin{array}{l}\text { Reactor } \\
\text { Volume } \\
\text { (L) }\end{array}$ & $\begin{array}{l}\text { Liquid } \\
\text { Volume } \\
\text { (L) }\end{array}$ & & \\
\hline String film (SFR) & 500 & 0.4 & 0.36 & 0.486 & 0.06 & $874.67^{\mathrm{L}}$ & This study \\
\hline Stirred tank (900 rpm) & 400 & - & - & 3.5 & 2.5 & $114^{\mathrm{R}}$ & [11] \\
\hline Stirred tank (1000 rpm) & 5000 & - & - & 2.44 & 1.77 & $216^{R}$ & [12] \\
\hline Bubble column & - & - & 1.2 & 8.64 & 6.90 & $180^{\mathrm{R}}$ & [17] \\
\hline Bubble column & - & - & 10.8 & 22 & 4.0 & $360^{R}$ & [16] \\
\hline Bubble column & 10,000 & - & 0.93 & 32 & 11 & $126^{\mathrm{R}}$ & [32] \\
\hline Air-lift & - & - & $1.77-7.07$ & 1.75 & 0.85 & $360^{R}$ & {$[20]$} \\
\hline Packed bed-trickle flow & 131 & 0.05 & - & 1.2 & 0.0081 & $421^{\mathrm{L}}$ & [11] \\
\hline Hollow fiber membrane & 1000 & 0.4 & - & - & 0.018 & $1062^{\mathrm{L}}$ & [11] \\
\hline
\end{tabular}

To evaluate the SFR, it should be considered that the effective volume of liquids for gas absorption in the entire system is small. The reactor-volume-based $k_{L} a$ is reduced when the system volume is used as the basis of the calculation, while the liquid-volume-based $k_{L} a$ is very high. It is expected that many of the drawbacks resulting from a low effective volume can be addressed easily by increasing the number of strings in the system. Nevertheless, by comparing the performance of the SFR with a stirred tank, bubble column, or air-lift reactor that injects gas directly into the system, the required costs for system installation and energy consumption, as well as the mass transfer performance, should be assessed thoroughly. 


\section{Materials and Methods}

\subsection{Schematic of the String Film Reactor (SFR)}

A schematic of the SFR is shown in Figure 6. The SFR was made of acrylic plastic with an inner diameter of $5.08 \mathrm{~cm}$ and a total height of $44 \mathrm{~cm}$. It was equipped with a water jacket to maintain the temperature.

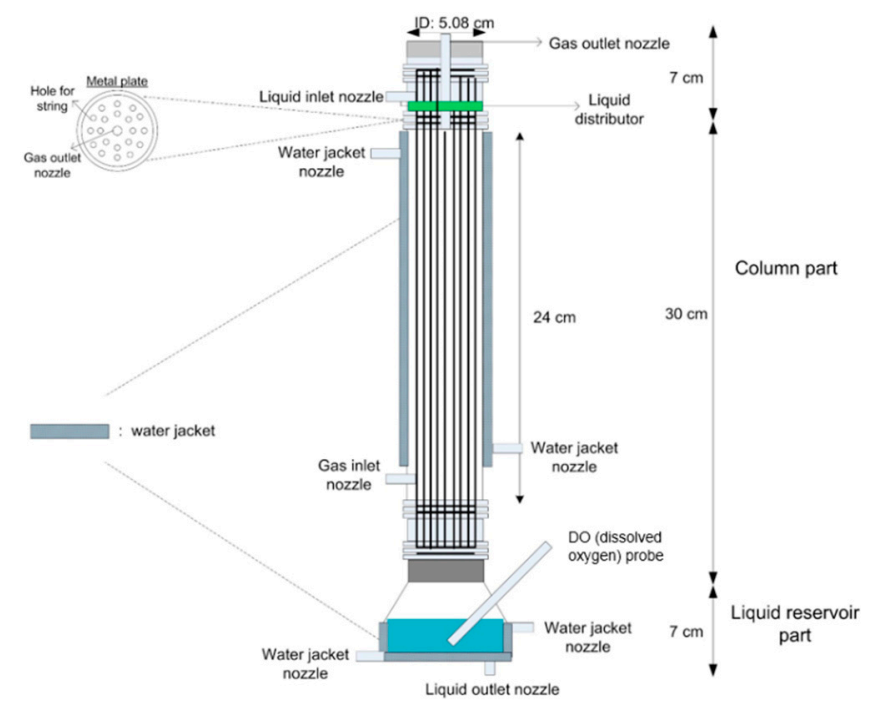

Figure 6. Schematic diagram of the string film reactor.

The SFR had two main parts, i.e., a column part and a liquid reservoir part. The column part, where the contact between liquid and gas took place, had a total volume of $486 \mathrm{~mL}$ with a void fraction of 0.92 , and consisted of 20 strings with a diameter of $0.3175 \mathrm{~cm}$ and an effective length of $24 \mathrm{~cm}$. The strings were held using a metal plate that was placed on the top and lower parts of the column part; the plate consisted of 20 holes with a diameter of $0.4 \mathrm{~cm}$, as shown in Figure 6 . The bottom of the SFR acted as a liquid reservoir for dissolved oxygen and dissolved methane measurements. The liquid distributor, which was made of hydrophilic natural pulp material, was placed on the metal plate.

\subsection{Experimental Procedure for Gas-Liquid Contact Using the SFR System}

The mass transfer performance of the SFR was determined in the absence of microorganism cells. The experimental setup employed for measuring the mass transfer performance of the SFR is shown in Figure 7 . The experiments were performed at $30^{\circ} \mathrm{C}$ and atmospheric pressure, which is the process condition typically used in the aerobic bioconversion of methane. Double-distilled water from a water holding tank, which was initially purged using nitrogen to obtain a DO value close to $0 \%$, was fed to the SFR using a peristaltic pump (BT301L, Lead Fluid, Baoding, China) at a desired flow rate. The air or air-methane from the gas tank was fed directly to the SFR by adjusting the flow rate using a mass flow controller. The SFR was operated in counter current mode. Various gas $(0.03-0.5 \mathrm{~L} / \mathrm{min})$ and liquid (100-500 $\mathrm{mL} / \mathrm{min})$ flow rates were tested.

In the case of air, a DO probe (Oxyprobe D500, Broadly James, Irvine, CA, USA) was placed in the liquid reservoir and connected to a fermentor control unit (CNS, South Korea) for data acquisition. The DO values were observed and recorded every $30 \mathrm{~s}$ until the system reached steady state, which was determined when the DO value did not change within a 3 min period. In the case of methane, its dissolved concentration was measured using a collection tube (BD vacutainer ${ }^{\circledR}$, Becton Dickinson, Franklin Lakes, NJ, USA) and a gas chromatograph (6890N, Agilent, Santa Clara, CA, USA). When the system reached a steady state, a specific amount of the liquid in the reservoir was drawn by a $B D$ vacutainer, which is a plastic test tube with a rubber stopper creating a vacuum seal inside 
of the tube. The amount of dissolved methane concentration was calculated by comparing using Gas Chromatography (GC) the gas composition before and after sampling. Runs were performed in triplicate for each test condition.

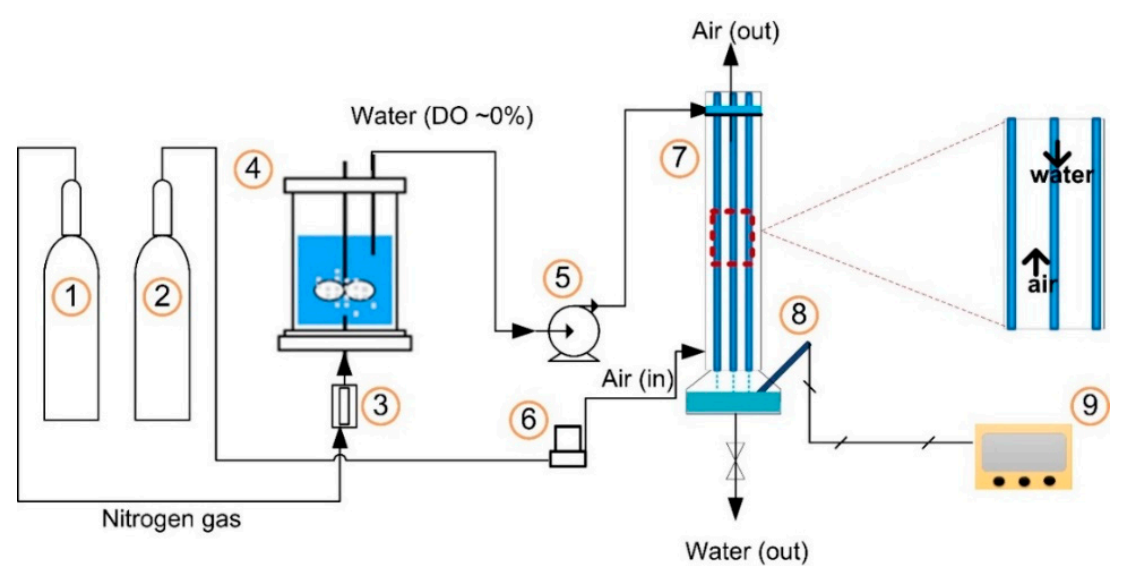

Figure 7. Mass transfer experiment setup: (1) Nitrogen gas tank; (2) Air (or air-methane) gas tank; (3) Nitrogen gas rotameter; (4) Water holding tank; (5) Peristaltic pump; (6) Mass flow controller; (7) SFR; (8) DO electrode; and (9) Data acquisition unit.

\subsection{Determination of Volumetric Mass Transfer Performance}

The mass transfer performance was determined by calculating the value of the volumetric liquid-side mass transfer coefficient $k_{L} a$. The formula used to calculate the volumetric liquid-side mass transfer coefficient $k_{L} a$ was obtained by deriving the oxygen mass balance in the liquid, as described below.

$$
\frac{d C}{d t}=k_{L} a\left(C^{*}-C\right)
$$

Integrating each side of Equation (1), Equation (2) could be obtained as follows:

$$
\ln \frac{C^{*}-C_{0}}{C^{*}-C_{f}}=k_{L} a\left(t_{f}-t_{0}\right)
$$

where $C_{0}$ and $C_{f}$ are the dissolved gas concentrations at the starting point and end point in the system, respectively. In the SFR, $C_{f}$ does not change with time when it is in steady state, and $t_{f}$ denotes the residence time of liquid in the system; $k_{L} a$ can be derived using the liquid volume, the liquid flow rate, and the variation in the dissolved gas concentrations:

$$
\therefore k_{L} a=\frac{Q_{L}}{V} \ln \frac{C^{*}-C_{0}}{C^{*}-C_{s}}
$$

where $Q_{L}$ is the liquid flow rate and $C_{s}$ is the dissolved concentration of the gases in the steady state.

\section{Conclusions}

The SFR was able to perform gas transfer to the liquid with a simple configuration and achieved a large volumetric liquid-side mass transfer coefficient $k_{L} a$. When comparing the mass transfer performance for the cases with air, methane, and air-methane mixed gas, the mass transfer coefficient did not change significantly, showing the independent transfer behavior of oxygen and methane.

The mass transfer of the SFR was determined using three main parameters:

1. The liquid flow rate, which had a significant effect on the mass transfer performance; 
2. The gas flow rate, where the mass transfer performance increased with gas flow rate values below the critical gas flow rate, while it was almost constant above the critical rate. The value of the critical gas flow rate depends on the liquid flow rate;

3. The hydrophilicity of the string material, where a more hydrophilic material could significantly improve the mass transfer performance.

Therefore, for either the operation or further development of the SFR, the above three parameters should be considered. Furthermore, the SFR exhibited good potential as an alternative to the existing types of bioreactor owing to its high mass transfer performance and simplicity.

Author Contributions: Conceptualization, J.-G.N.; Data curation, R.M. and J.-G.N.; Formal analysis, T.W.K. and B.-K.O.; Investigation, R.M., M.-S.K., C.I.L. and T.W.K.; Methodology, M.-S.K. and C.I.L.; Supervision, J.L. and J.-G.N.; Validation, T.W.K., S.J.P., B.-K.O., J.L. and J.-G.N.; Writing—original draft, R.M.; Writing—review \& editing, S.J.P. and J.-G.N.

Funding: This research was supported by the C1 Gas Refinery Program through NRF funded by the Ministry of Science and ICT (NRF-2015M3D3A1A01064926) and "Human Resources Program in Energy Technology" of the Korea Institute of Energy Technology Evaluation and Planning (KETEP), granted financial resources from the Ministry of Trade, Industry \& Energy, Republic of Korea (No. 20174010201150).

Conflicts of Interest: The authors declare no conflict of interest.

\section{References}

1. Fei, Q.; Guarnieri, M.T.; Tao, L.; Laurens, L.M.L.; Dowe, N.; Pienkos, P.T. Bioconversion of natural gas to liquid fuel: Opportunities and challenges. Biotechnol. Adv. 2014, 32, 596-614. [CrossRef] [PubMed]

2. U.S. Energy Information Administration, Annual Energy Outlook 2012 with Projections to 2035 (EIA Publication 0383, 2012). Available online: https:/ /www.eia.gov/outlooks/archive/aeo12/ (accessed on 23 October 2018).

3. Kidanu, W.G.; Trang, P.T.; Yoon, H.H. Hydrogen and volatile fatty acids production from marine macroalgae by anaerobic fermentation. Biotechnol. Bioproc. Eng. 2017, 22, 612-619. [CrossRef]

4. Conrado, R.J.; Gonzalez, R. Envisioning the bioconversion of methane to liquid fuels. Science 2014, 343, 621-623. [CrossRef] [PubMed]

5. Hur, D.H.; Na, J.-G.; Lee, E.Y. Highly efficient bioconversion of methane to methanol using a novel type I Methylomonas sp. DH-1 newly isolated from brewery waste sludge. J. Chem. Technol. Biotechnol. 2017, 92, 311-318. [CrossRef]

6. Canul-Chan, M.; Chable-Naal, J.; Rojas-Herrera, R.; Zepeda, A. Hydrocarbon degradation capacity and population dynamics of a microbial consortium obtained using a sequencing batch reactor in the presence of molasses. Biotechnol. Bioproc. Eng. 2017, 22, 170-177. [CrossRef]

7. David, Y.; Baylon, M.G.; Pamidimarri, S.D.V.N.; Baritugo, K.-A.; Chae, C.G.; Kim, Y.J.; Kim, T.W.; Kim, M.S.; Na, J.-G.; Park, S.J. Screening of microorganisms able to degrade low-rank coal in aerobic conditions: Potential coal biosolubilization mediators from coal to biochemical. Biotechnol. Bioproc. Eng. 2017, 22, 178-185. [CrossRef]

8. Lee, J.W.; Kim, H.U.; Choi, S.; Yi, J.; Lee, S.Y. Microbial production of building block chemicals and polymers. Curr. Opin. Biotechnol. 2011, 22, 758-767. [CrossRef] [PubMed]

9. Nguyen, A.D.; Hwang, I.Y.; Lee, O.K.; Kim, D.; Kalyuzhnaya, M.G.; Mariyana, R.; Hadiyati, S.; Kim, M.S.; Lee, E.Y. Systematic metabolic engineering of Methylomicrobium alcaliphilum 20Z for 2,3-butanediol production from methane. Metab. Eng. 2018, 47, 323-333. [CrossRef] [PubMed]

10. Kim, M.S.; Fitriana, H.N.; Kim, T.W.; Kang, S.G.; Jeon, S.G.; Chung, S.H.; Park, G.W.; Na, J.-G. Enhancement of the hydrogen productivity in microbial water gas shift reaction by Thermococcus onnurineus NA1 using a pressurized bioreactor. Int. J. Hydrogen Energy. 2017, 42, 27593-27599. [CrossRef]

11. Orgill, J.J;; Atiyeh, H.K.; Devarapalli, M.; Phillips, J.R.; Lewis, R.S.; Huhnke, R.L. A comparison of mass transfer coefficients between trickle-bed, hollow fiber membrane and stirred tank reactors. Bioresour. Technol. 2013, 133, 340-346. [CrossRef] [PubMed] 
12. Karimi, A.; Golbabaei, F.; Mehrnia, M.R.; Neghab, M.; Mohammad, K. Oxygen mass transfer in a stirred tank bioreactor using different impeller configurations for environmental purposes. Iranian J. Environ. Health Sci. Eng. 2013, 10. [CrossRef] [PubMed]

13. Bredwell, M.D.; Worden, R.M. Mass-transfer properties of microbubbles. 1. Experimental Studies. Biotechnol. Prog. 1998, 14, 31-38. [CrossRef] [PubMed]

14. Munasinghe, P.C.; Khanal, S.K. Syngas fermentation to biofuel: evaluation of carbon monoxide mass transfer and analytical modeling using a composite hollow fiber (chf) membrane bioreactor. Bioresour. Technol. 2012, 122, 130-136. [CrossRef] [PubMed]

15. Lee, P.-H.; Ni, S.-Q.; Chang, S.-Y.; Sung, S.; Kim, S.-H. Enhancement of carbon monoxide mass transfer using an innovative external hollow fiber membrane $(\mathrm{hfm})$ diffuser for syngas fermentation: experimental studies and model development. Chem. Eng. J. 2012, 184, 268-277. [CrossRef]

16. Lau, R.; Lee, P.H.V.; Chen, T. Mass transfer studies in shallow bubble column reactors. Chem. Eng. Process. 2012, 62, 18-25. [CrossRef]

17. Krishna, R.; Ellenberger, J. Improving gas-liquid contacting in bubble columns by vibration excitement. Int. J. Multiph. Flow 2002, 28, 1223-1234. [CrossRef]

18. Kim, Z.H.; Park, Y.S.; Ryu, Y.J.; Lee, C.G. Enhancing biomass and fatty acid productivity of Tetraselmis sp. in bubble column photobioreactors by modifying light quality using light filters. Biotechnol. Bioproc. Eng. 2017, 22, 397-404. [CrossRef]

19. Jajuee, B.; Margaritis, A.; Karamanev, D.; Bergougnou, M.A. Mass transfer characteristics of a novel three-phase airlift contactor with a semipermeable membrane. Chem. Eng. J. 2006, 125, 119-126. [CrossRef]

20. Bekassy-Molnar, E.; Majeed, J.G.; Vatai, G. Overall volumetric oxygen transfer coefficient and optimal geometry of airlift tube reactor. Chem. Eng. J. 1997, 68, 29-33. [CrossRef]

21. Bredwell, M.D.; Srivastava, P.; Worden, R.M. Reactor design issues for synthesis-gas fermentations. Biotechnol. Prog. 1999, 15, 834-844. [CrossRef] [PubMed]

22. Satterfield, C.N.; Pelossof, A.A.; Sherwood, T.K. Mass transfer limitations in a trickle-bed reactor. AIChE J. 1969, 15, 226-234. [CrossRef]

23. Qureshi, N.; Annous, B.A.; Ezeji, T.C.; Karcher, P.; Maddox, I.S. Biofilm reactors for industrial bioconversion processes: Employing potential of enhanced reaction rates. Microb. Cell. Fact. 2005, 4. [CrossRef] [PubMed]

24. Arkles, B. Hydrophobicity, Hydrophilicity and Silanes. Paint \& Coat. Ind. 2006. Available online: https:/ /www.pcimag.com/ext/resources/PCI/Home/Files/PDFs/Virtual_Supplier_Brochures / Gelest_Additives.pdf (accessed on 23 October 2018).

25. Vasiljevic, J.; Tomsic, B.; Jerman, I.; Simoncic, B. Organofunctional Trialkoxysilane Sol-Gel Precursors for Chemical Modification of Textile Fibres. Tekstilec 2017, 60, 198-213. [CrossRef]

26. Critical Surface Tension and Contact Angle with Water for Various Polymers. Available online: https: / / www.accudynetest.com/polytable_03.html?sortby_contact_angle (accessed on 13 October 2018).

27. Charpentier, J.C. Mass transfer in gas-liquid absorbers and reactors. Adv. Chem. Eng. 1981, 11, 1-123. [CrossRef]

28. Onda, K.; Takeuchi, H.; Okumoto, Y. Gas absorption with chemical reaction in packed column. J. Chem. Eng. Jpn. 1968, 1, 62-66. [CrossRef]

29. Han, M.W.; Lee, W.K.; Choi, D.K. Effect of shape and wettability of packing materials on the efficiency of packed column. Korean J. Chem. Eng. 1985, 2, 25-31. [CrossRef]

30. Garcia-Ochoa, F.; Gomez, E. Bioreactor scale-up and oxygen transfer rate in microbial processes: An overview. Biotechnol. Adv. 2009, 27, 153-176. [CrossRef] [PubMed]

31. Mass Diffusivity. Available online: https://en.wikipedia.org/wiki/Mass_diffusivity (accessed on 24 September 2018).

32. Budzynski, P.; Gwiazda, A.; Dziubinski, M. Intensification of mass transfer in a pulsed bubble column. Chem. Eng. Process. 2017, 112, 18-30. [CrossRef]

(C) 2018 by the authors. Licensee MDPI, Basel, Switzerland. This article is an open access article distributed under the terms and conditions of the Creative Commons Attribution (CC BY) license (http:/ / creativecommons.org/licenses/by/4.0/). 